\title{
STOCHASTIC MODEL OF HUMAN GESTATION PERIOD FOR MATURE AND PREMATURE LIVE BIRTH
}

\author{
K. SENTHAMARAI KANNAN, D. NAGARAJAN AND T. TAMIZH CHELVAM
}

\begin{abstract}
The Gestation period or the Infecundable period of pregnancy measure from the date of conception to the date of termination of pregnancy by live birth is a useful item for the consideration in certain demographic, biological and public health problems. Bartholomew (1973) has analysed some Markov Chain Model. In this paper, the equilibrium state of human gestation period for mature and premature live birth are analysed. The demographic and biological character of mothers are discussed through the data collected from the hospitals.
\end{abstract}

\section{Introduction}

This paper analyzes the estimation of relative frequencies of probability of meats used in various period, extrapolates the relative proportion of meats over the long run. The hospital records 500 mothers who delivered live births are analyzed with respect to the duration of human gestation and the maturity status of the present child whether the present birth is matured or prematured.

The relevant data were obtained from government hospital, Nagercoil, Kanniyakumari District, Tamil Nadu, India from October 1, 2001 to December 31, 2001.

The hospital has good maternity facility which covers a population of 1.5 lakhs. The average number of daily out patients and inpatients is 200 and 300 respectively. This hospital also records systematically the information about various bio-demographic characteristics of the pregnant women. The prematured birth is defined as a birth weight less than 2,500g and if the birth weight is greater than 2,500g it is defined as matured baby. Low birth weight is public health importance because of the strong relationship between birth weight and infant mortality and morbidity. Therefore, it is possible to study the variability during gestation period both, in the case of the mature as well as premature births. This finding is in conformity with observations made by Srinivasan et al. (1986) and Senthamarai Kannan et al. (2002).

Received December 9, 2003; revised September 23, 2004.

2000 Mathematics Subject Classification. 60G.

Key words and phrases. Stochastic, equilibrium, mean passage time.

Part of this paper have presented and accepted for publication in proceedings of Seventh Conference of International Biometric Society (Indian Region) 2003, at Banaras Hindu University, Varanasi, India. 


\section{Data}

During October 1, 2001 to December 31, 2001 a total of 544 pregnant cases were registered in the hospital. Among them the information about last menstrual period is not available for 44 cases, out of the remaining 500 cases the number of mature births were 379 and the number of premature births were 121.

For each of 500 mothers, the following data were collected from hospital case sheets.

- Age of the women at the time of delivery.

- Parity of the women.

- Blood group.

- Haemoglobin (HB) content.

Table 1 presents the distribution of the duration of gestation of mature birth according to the demographic and biological character of the mothers.

Table 1. Distribution of the duration of Gestation for the mature live birth by age, parity, HB contents, blood group of the mothers.

\begin{tabular}{|c|c|c|c|c|}
\hline \multirow{2}{*}{$\begin{array}{l}\text { Characteristics } \\
\text { of the mothers }\end{array}$} & \multicolumn{4}{|c|}{ Duration of Gestation (days) } \\
\hline & $210-238$ & $238-266$ & $266-280$ & $280-308$ \\
\hline \multicolumn{5}{|l|}{ Age } \\
\hline $15-19$ & 17 & 5 & 15 & 14 \\
\hline $20-24$ & 16 & 48 & 110 & 16 \\
\hline $25-29$ & 14 & 24 & 42 & 11 \\
\hline 30-above & 12 & 3 & 14 & 18 \\
\hline \multicolumn{5}{|l|}{ Parity } \\
\hline 0 & 27 & 44 & 134 & 35 \\
\hline 1 & 8 & 18 & 20 & 10 \\
\hline 2 & 3 & 15 & 15 & 7 \\
\hline $3+$ & 10 & 13 & 13 & 7 \\
\hline \multicolumn{5}{|c|}{ HB content in grams } \\
\hline 7.9 & 4 & 8 & 1 & 2 \\
\hline $8.0-9.9$ & 20 & 26 & 16 & 23 \\
\hline $10.0-11.9$ & 18 & 33 & 160 & 28 \\
\hline $12.0-13.0$ & 6 & 23 & 5 & 6 \\
\hline \multicolumn{5}{|l|}{ Blood Group } \\
\hline $\mathrm{A}$ & 10 & 6 & 10 & 9 \\
\hline $\mathrm{B}$ & 41 & 23 & 170 & 28 \\
\hline $\mathrm{AB}$ & 7 & 8 & 2 & 15 \\
\hline $\mathrm{O}$ & 30 & 13 & 0 & 7 \\
\hline
\end{tabular}

Table 2 presents the distribution of the duration of gestation of premature birth according to the demographic and biological character of the mothers. 
Table 2. Distribution of the duration of Gestation for the premature live birth by age, parity, HB contents, blood group of the mothers.

\begin{tabular}{|l|c|c|c|c|}
\hline \multirow{5}{*}{$\begin{array}{l}\text { Characteristics } \\
\text { of the mothers }\end{array}$} & \multicolumn{5}{|c|}{ Duration of Gestation (days) } \\
\cline { 2 - 5 } & $210-238$ & $238-266$ & $266-280$ & $280-308$ \\
\hline Age & 1 & 3 & 11 & 5 \\
\hline $15-19$ & 4 & 6 & 40 & 10 \\
\hline $20-24$ & 2 & 2 & 7 & 4 \\
\hline $25-29$ & 2 & 7 & 14 & 3 \\
\hline $30-$-above & 2 & 9 & 57 & 12 \\
\hline Parity & 1 & 2 & 8 & 3 \\
\hline 0 & 2 & 1 & 4 & 3 \\
\hline 1 & 4 & 6 & 3 & 4 \\
\hline 2 & 2 & 1 & 3 & 4 \\
\hline $3+$ & 2 & 3 & 8 & 7 \\
\hline HB Content in grams & 4 & 7 & 52 & 8 \\
\hline 7.9 & 1 & 7 & 9 & 3 \\
\hline $8.0-9.9$ & 1 & 2 & 11 & 3 \\
\hline $10.0-11.9$ & 4 & 9 & 42 & 11 \\
\hline $12.0-13.0$ & 1 & 1 & 3 & 3 \\
\hline Blood Group & 3 & 6 & 16 & 5 \\
\hline A & \multicolumn{5}{|l|}{} \\
\hline B & \multicolumn{5}{|l|}{} \\
\hline AB & &
\end{tabular}

From Table 1 and Table 2, it can be seen that 379 births (75.80\%) were matured and $121(24.20 \%)$ were prematured. Most of the women were between 20-29 years with a major concentration towards the left side. Only about $14.8 \%$ of the women were observed bearing children after the age of 30. A low proportion of births in the age group 15-19 of the women might be due to the higher age at marriage in the Nagercoil. Chances of births to be prematured were higher at the younger ages and appeared to decrease with the increase in the age of the mother. This finding is in conformity with the observations made by Srinivasan et al. (1986) and Prithiviraj C.A. and Senthamarai Kannan K. (1998) and Senthamarai Kannan et al. (2002).

\section{Equilibrium State of Gestation Period for Mature Birth}

Dividing each fij element by its row-sum produces the matrix of transition probabilities, $P$. In Table 3 , all $P i j$ 's are non negative and each rwo sums to unity. Thus, $P$ provides the probabilities of remaining in or changing state over the period of intervals. 
Table 3. Transition Matrix of the duration of Gestation for Mature Live Birth by age, parity, HB content and Blood Group of the mothers.

\begin{tabular}{|l|c|c|c|c|}
\hline \multirow{5}{*}{$\begin{array}{l}\text { Characteristics } \\
\text { of the mothers }\end{array}$} & \multicolumn{5}{|c|}{ Duration of Gestation (days) } \\
\cline { 2 - 5 } & $210-238$ & $238-266$ & $266-280$ & $280-308$ \\
\hline Age & .3333 & .0980 & .2941 & .2745 \\
\hline $15-19$ & .0842 & .2526 & .5789 & .0842 \\
\hline $20-24$ & .1538 & .2637 & .4615 & .1208 \\
\hline $25-29$ & .2553 & .0638 & .2978 & .3829 \\
\hline 30 -above & .1125 & .1833 & .5583 & .1458 \\
\hline Parity & .1428 & .3214 & .3571 & .1785 \\
\hline 0 & .0750 & .3750 & .3750 & .1750 \\
\hline 1 & .2325 & .3023 & .3023 & .1627 \\
\hline 2 & .2666 & .5333 & .0666 & .1333 \\
\hline $3+$ & .2352 & .3058 & .1882 & .2705 \\
\hline HB content in grams & .0753 & .1380 & .6694 & .1171 \\
\hline 7.9 & .0251 & .0962 & .0209 & .0251 \\
\hline $8.0-9.9$ & .561 & .1711 & .2861 & .2571 \\
\hline $10.0-11.9$ & .1561 & .2880 & .6491 & .1071 \\
\hline $12.0-13.0$ & .2190 & .2500 & .0631 & .4692 \\
\hline Blood Group & .6000 & .2600 & 0000 & .1410 \\
\hline A & \multicolumn{5}{|l|}{} \\
\hline B & \multicolumn{5}{|l|}{} \\
\hline AB &
\end{tabular}

With the data transformed into these arrays we can use some matrix algebra and apply the chapman kolmogrove's theorems of Markov Chains (Kemney, 1960)

$$
P^{(t+n)}=P^{t} \cdot P^{n}
$$

where $P^{t}$ is a row vector the ordered components of which denotes the initial probability distribution across the state $P^{n}$ is the matrix of transition probability, $n$ is an exponent indicating the number of trials.

\subsection{Age group of the Mothers by mature live birth}

The initial probability distribution $P^{t}$ can be found by dividing the frequency of each element by the sum thus $(0.2,0.1,0.5,0.2)$.

$$
P^{t}=(.2, .1, .5, .2)
$$




$$
\begin{aligned}
& P^{2}=\left[\begin{array}{l}
.2346 .1542 .3150 .2403 \\
.1598 .2300 .3621 .1465 \\
.1752 .2110 .4302 .1664 \\
.2340 .1440 .3611 .2580
\end{array}\right] \\
& P^{(t+2)}=\left[\begin{array}{llll}
.1970 & .1870 & .3860 & .1975
\end{array}\right]
\end{aligned}
$$

The ultimate equilibrium vector, $P^{e}$, contains four components, so we pre-multiply $P$ by four component row vectors of unknown $\left(x_{1}, x_{2}, x_{3}, x_{4}\right)$.

A system of four equation is produced plus the equation

or

$$
X_{1}+X_{2}+X_{3}+X_{4}=1
$$

$$
\begin{aligned}
& .3333 X_{1}+.0842 X_{2}+.1538 X_{3}+.2533 X_{4}=X_{1} \\
& .0980 X_{1}+.2556 X_{2}+.2637 X_{3}+.0638 X_{4}=X_{2} \\
& .2941 X_{1}+.5789 X_{2}+.4615 X_{3}+.2978 X_{4}=X_{3} \\
& .2745 X_{1}+.0842 X_{2}+.1208 X_{3}+.3529 X_{4}=X_{4}
\end{aligned}
$$

and

$$
X_{1}+X_{2}+X_{3}+X_{4}=1 .
$$

When these equations are solved simultaneously we get the equilibrium vector $P^{e}$

$$
P^{e}=(.1778, .1938, .4279, .2003) .
$$

This equation specifies the long term expected properties. A $\chi^{2}$ test of goodness of fit with 3 degrees of freedom where

$$
\chi^{2}=\sum_{I=1,2,3,4} \frac{(O-E)^{2}}{E}=7.5
$$

and, where $O=$ obseved frequencies, $E=$ expected frequencies and $I$ is the number of state, has a probability $P>0.90$. This test shows that the expected and observed distribution do not differ significantly.

Table 4. Comparison of Expected and Actual Distribution.

\begin{tabular}{|c|c|c|c|}
\hline $\begin{array}{c}\text { Gestation } \\
\text { Period (days) }\end{array}$ & $\begin{array}{c}\text { Observed } \\
\text { Frequency }\end{array}$ & $\begin{array}{c}\text { Proportion } \\
\text { Expected }\end{array}$ & $\begin{array}{c}\text { Expected } \\
\text { Frequency }\end{array}$ \\
\hline $210-238$ & 59 & .1778 & 67.38 \\
\hline $238-266$ & 80 & .1932 & 73.45 \\
\hline $266-280$ & 181 & .4279 & 162.14 \\
\hline $280-308$ & 59 & .2008 & 75.91 \\
\hline
\end{tabular}




\subsection{Parity of the Mothers by mature live birth}

The initial probability distribution $P^{t}$ can be found by dividing the frequency of each element by the sum thus $(0.2,0.1,0.5,0.2)$.

$$
\begin{aligned}
& P^{t}=(.2, .1, .5, .2)
\end{aligned}
$$

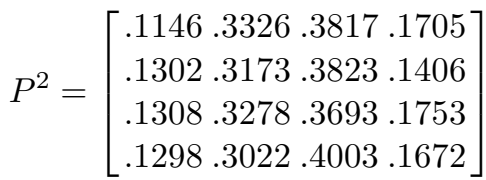

$$
\begin{aligned}
& P^{(t+2)}=\left[\begin{array}{llll}
.1273 & .3225 & .3792 & .1692
\end{array}\right]
\end{aligned}
$$

The ultimate equilibrium vector, $P^{e}$, contains four components, so we pre-multiply $P$ by four component row vectors of unknown $\left(x_{1}, x_{2}, x_{3}, x_{4}\right)$.

A system of four equation is produced plus the equation

$$
X_{1}+X_{2}+X_{3}+X_{4}=1
$$

or

$$
\begin{aligned}
& .1125 X_{1}+.1428 X_{2}+.0750 X_{3}+.2325 X_{4}=X_{1} \\
& .1833 X_{1}+.3214 X_{2}+.1750 X_{3}+.3023 X_{4}=X_{2} \\
& .5583 X_{1}+.3571 X_{2}+.3750 X_{3}+.3023 X_{4}=X_{3} \\
& .1458 X_{1}+.1785 X_{2}+.1750 X_{3}+.1627 X_{4}=X_{4}
\end{aligned}
$$

and

$$
X_{1}+X_{2}+X_{3}+X_{4}=1
$$

When these equations are solved simultaneously we get the equilibrium vector $P^{e}$

$$
P^{e}=(.1283, .3207, .3803, .1705) \text {. }
$$

This equation specifies the long term expected properties. A $\chi^{2}$ test of goodness of fit with 3 degrees of freedom where

$$
\chi^{2}=\sum_{I=1,2,3,4} \frac{(O-E)^{2}}{E}=37.5
$$

and, where $O=$ obseved frequencies, $E=$ expected frequencies and $I$ is the number of state, has a probability $P>0.90$. This test shows that the expected and observed distribution differ significantly.

Table 5. Comparison of Expected and Actual Distribution.

\begin{tabular}{|c|c|c|c|}
\hline $\begin{array}{c}\text { Gestation } \\
\text { Period (days) }\end{array}$ & $\begin{array}{c}\text { Observed } \\
\text { Frequency }\end{array}$ & $\begin{array}{c}\text { Proportion } \\
\text { Expected }\end{array}$ & $\begin{array}{c}\text { Expected } \\
\text { Frequency }\end{array}$ \\
\hline $210-238$ & 48 & .1185 & 48.62 \\
\hline $238-266$ & 90 & .3210 & 121.15 \\
\hline $266-280$ & 182 & .3793 & 144.13 \\
\hline $280-308$ & 59 & .1663 & 64.61 \\
\hline
\end{tabular}




\subsection{Haemoglobin content of the Mothers by mature live birth}

The initial probability distribution $P^{t}$ can be found by dividing the frequency of each element by the sum thus $(0.2,0.1,0.5,0.2)$.

$$
\begin{aligned}
& P^{t}=(.2, .1, .5, .2) \\
& P^{2}=\left[\begin{array}{llll}
.2214 & .3910 & .7930 & .2075 \\
.1893 & .4000 & .2329 & .1766 \\
.1205 & .2420 & .04937 & .1433 \\
.2070 & .3592 & .2205 & .2126
\end{array}\right] \\
& P^{(t+2)}=\left[\begin{array}{llll}
.1648 & .3110 & .3501 & .1733
\end{array}\right]
\end{aligned}
$$

The ultimate equilibrium vector, $P^{e}$, contains four components, so we pre-multiply $P$ by four component row vectors of unknown $\left(x_{1}, x_{2}, x_{3}, x_{4}\right)$.

A system of four equation is produced plus the equation

$$
X_{1}+X_{2}+X_{3}+X_{4}=1
$$

or

$$
\begin{aligned}
& .2666 X_{1}+.2352 X_{2}+.0753 X_{3}+.1500 X_{4}=X_{1} \\
& .5333 X_{1}+.3058 X_{2}+.1380 X_{3}+.5750 X_{4}=X_{2} \\
& .0666 X_{1}+.1880 X_{2}+.6694 X_{3}+.1250 X_{4}=X_{3} \\
& .1333 X_{1}+.2705 X_{2}+.1178 X_{3}+.1500 X_{4}=X_{4}
\end{aligned}
$$

and

$$
X_{1}+X_{2}+X_{3}+X_{4}=1
$$

When these equations are solved simultaneously we get the equilibrium vector $P^{e}$

$$
P^{e}=(.1729, .3294, .3416, .1560) \text {. }
$$

This equation specifies the long term expected properties. A $\chi^{2}$ test of goodness of fit with 3 degrees of freedom where

$$
\chi^{2}=\sum_{I=1,2,3,4} \frac{(O-E)^{2}}{E}=37.43
$$

and, where $O=$ obseved frequencies, $E=$ expected frequencies and $I$ is the number of state, has a probability $P>0.90$. This test shows that the expected and observed distribution differ significantly. 
Table 6. Comparison of Expected and Actual Distribution.

\begin{tabular}{|c|c|c|c|}
\hline $\begin{array}{c}\text { Gestation } \\
\text { Period (days) }\end{array}$ & $\begin{array}{c}\text { Observed } \\
\text { Frequency }\end{array}$ & $\begin{array}{c}\text { Proportion } \\
\text { Expected }\end{array}$ & $\begin{array}{c}\text { Expected } \\
\text { Frequency }\end{array}$ \\
\hline $210-238$ & 48 & .1729 & 65.52 \\
\hline $238-266$ & 90 & .3294 & 124.84 \\
\hline $266-280$ & 184 & .3416 & 129.46 \\
\hline $280-308$ & 59 & .1560 & 59.12 \\
\hline
\end{tabular}

\subsection{Blood Group of mothers by mature live birth}

The initial probability distribution $P^{t}$ can be found by dividing the frequency of each element by the sum thus $(0.2,0.1,0.5,0.2)$.

$$
\begin{aligned}
& P^{t}=(.2, .1, .5, .2) \\
& P^{2}=\left[\begin{array}{l}
.3250 .2020 .2110 .2620 \\
.2650 .2241 .1430 .3681 \\
.3961 .1982 .2290 .1780 \\
.2961 .1620 .3400 .2020
\end{array}\right] \\
& P^{(t+2)}=\left[\begin{array}{llll}
.3300 & .1900 & .2500 & .2300
\end{array}\right] \text {. }
\end{aligned}
$$

The ultimate equilibrium vector, $P^{e}$, contains four components, so we pre-multiply $P$ by four component row vectors of unknown $\left(x_{1}, x_{2}, x_{3}, x_{4}\right)$.

A system of four equation is produced plus the equation

$$
X_{1}+X_{2}+X_{3}+X_{4}=1
$$

or

$$
\begin{aligned}
.286 X_{1}+.156 X_{2}+.219 X_{3}+.6 X_{4} & =X_{1} \\
.171 X_{1}+.088 X_{2}+.25 X_{3}+.26 X_{4} & =X_{2} \\
.286 X_{1}+.649 X_{2}+.063 X_{3}+0 X_{4} & =X_{3} \\
.257 X_{1}+.107 X_{2}+.469 X_{3}+.14 X_{4} & =X_{4}
\end{aligned}
$$

and

$$
X_{1}+X_{2}+X_{3}+X_{4}=1
$$

When these equations are solved simultaneously we get the equilibrium vector $P^{e}$

$$
P^{e}=(.323, .196, .234, .247)
$$

This equation specifies the long term expected properties. A $\chi^{2}$ test of goodness of fit with 3 degrees of freedom where

$$
\chi^{2}=\sum_{I=1,2,3,4} \frac{(O-E)^{2}}{E}=128.6
$$


and, where $O=$ obseved frequencies, $E=$ expected frequencies and $I$ is the number of state, has a probability $P>0.90$. This test shows that the expected and observed distribution differ significantly.

Table 7. Comparison of Expected and Actual Distribution.

\begin{tabular}{|c|c|c|c|}
\hline $\begin{array}{c}\text { Gestation } \\
\text { Period (days) }\end{array}$ & $\begin{array}{c}\text { Observed } \\
\text { Frequency }\end{array}$ & $\begin{array}{c}\text { Proportion } \\
\text { Expected }\end{array}$ & $\begin{array}{c}\text { Expected } \\
\text { Frequency }\end{array}$ \\
\hline $210-238$ & 88 & .323 & 122.4 \\
\hline $238-266$ & 50 & .196 & 74.28 \\
\hline $266-280$ & 182 & .234 & 88.68 \\
\hline $280-308$ & 59 & .247 & 93.61 \\
\hline
\end{tabular}

Table 8. Mean First Passage Time.

\begin{tabular}{|c|c|c|c|c|c|}
\hline & Age Group & $210-238$ & $238-266$ & $266-280$ & $280-308$ \\
\hline & $15-19$ & 2.5 & 2.8 & 2.2 & 2.4 \\
\hline $\mathrm{M}$ & $20-24$ & 2.6 & 1.9 & 2.0 & 3.3 \\
\hline & $25-29$ & 2.5 & 2.1 & 2.2 & 3.0 \\
\hline & 30 -above & 2.8 & 2.8 & 2.0 & 2.2 \\
\hline \multicolumn{5}{|c|}{ Parity } \\
\hline \multicolumn{7}{|c|}{0} & 2.7 & 2.1 & 1.9 & 3.1 \\
\hline & 1 & 2.5 & 2.1 & 2.4 & 2.8 \\
\hline & 2 & 2.6 & 1.9 & 2.4 & 2.9 \\
\hline & $3+$ & 2.3 & 2.3 & 2.5 & 2.7 \\
\hline & HB content & 2.0 & 2.1 & 3.2 & 2.5 \\
\hline & 7.9 & 2.4 & 2.4 & 2.6 & 2.4 \\
\hline & $8-9.9$ & 2.8 & 2.1 & 1.6 & 3.3 \\
\hline & $10-11.9$ & .3 & .3 & .5 & .4 \\
\hline & $12-13$ & & & \\
\hline & Blood Group & 2.51 & 2.65 & 2.34 & 2.48 \\
\hline & A & 2.71 & 2.33 & 1.68 & 3.27 \\
\hline & B & 2.78 & 2.65 & 2.65 & 1.91 \\
\hline & AB & 1.68 & 3.08 & 3.12 & 2.12 \\
\hline & O & & \\
\hline
\end{tabular}

Each mij element denotes the number of trials (days) it will be (on average) before a particular distribution is used. 


\section{Equilibrium State of Gestation Period for Premature Birth}

Table 9. Transition Matrix of the Duration of Gestation Period for the premature live birth by age, parity, HB content \& Blood Group of the mothers.

\begin{tabular}{|l|c|c|c|c|}
\hline \multirow{5}{*}{$\begin{array}{l}\text { Characteristics } \\
\text { of the mothers }\end{array}$} & \multicolumn{5}{|c|}{ Duration of Gestation (days) } \\
\cline { 2 - 5 } & $210-238$ & $238-266$ & $266-280$ & $280-308$ \\
\hline Age & .0500 & .1500 & .5500 & .2500 \\
\hline $15-19$ & .0660 & .1000 & .6660 & .1660 \\
\hline $20-24$ & .1330 & .1330 & .4666 & .2660 \\
\hline $25-29$ & .0760 & .2692 & .5384 & .1156 \\
\hline 30 -above & .0250 & .1125 & .7125 & .1500 \\
\hline Parity & .0714 & .1428 & .5714 & .2142 \\
\hline 0 & .2000 & .1000 & .4000 & .3000 \\
\hline 1 & .2352 & .3529 & .1764 & .2352 \\
\hline 2 & .2000 & .1000 & .3000 & .4000 \\
\hline $3+$ & .1000 & .1500 & .4000 & .3500 \\
\hline HB Content in grams & .0563 & .0985 & .7323 & .1126 \\
\hline 7.9 & .0500 & .3500 & .4500 & .1500 \\
\hline $8.0-9.9$ & .5600 & .1200 & .6500 & .1800 \\
\hline $10.0-11.9$ & .0601 & .1400 & .6400 & .1700 \\
\hline $12.0-13.0$ & .1310 & .1300 & .3800 & .3800 \\
\hline Blood Group & .1100 & .2000 & .5300 & .1700 \\
\hline A & \multicolumn{5}{|l|}{} \\
\hline B &
\end{tabular}

\subsection{Age group of the Mothers by premature live birth}

The initial probability distribution $P^{t}$ can be found by dividing the frequency of each element by the sum thus $(0.1,0.2,0.5,0.2)$.

$$
\begin{aligned}
& P^{t}=(.1, .2, .5, .2) \\
& P^{2}=\left[\begin{array}{l}
.1045 .1629 .5183 .2126 \\
.1110 .1532 .5026 \\
.2294 \\
.0970 .1672 .5226 .2101 \\
.1010 .1410 .5345 .2201
\end{array}\right] \\
& P^{(t+2)}=\left[\begin{array}{llll}
.1015 & .1587 & .5205 & .12156
\end{array}\right] .
\end{aligned}
$$

The ultimate equilibrium vector, $P^{e}$, contains four components, so we pre-multiply $P$ by four component row vectors of unknown $\left(x_{1}, x_{2}, x_{3}, x_{4}\right)$. 
A system of four equation is produced plus the equation

$$
X_{1}+X_{2}+X_{3}+X_{4}=1
$$

or

$$
\begin{aligned}
& .0500 X_{1}+.0660 X_{2}+.1330 X_{3}+.0760 X_{4}=X_{1} \\
& .1500 X_{1}+.1000 X_{2}+.1330 X_{3}+.2692 X_{4}=X_{2} \\
& .5500 X_{1}+.6660 X_{2}+.4666 X_{3}+.5384 X_{4}=X_{3} \\
& .2500 X_{1}+.1660 X_{2}+.2666 X_{3}+.1156 X_{4}=X_{4}
\end{aligned}
$$

and

$$
X_{1}+X_{2}+X_{3}+X_{4}=1
$$

When these equations are solved simultaneously we get the equilibrium vector $P^{e}$

$$
P^{e}=(.0781, .1669, .5364, .2184) \text {. }
$$

This equation specifies the long term expected properties. A $\chi^{2}$ test of goodness of fit with 3 degrees of freedom where

$$
\chi^{2}=\sum_{I=1,2,3,4} \frac{(O-E)^{2}}{E}=1.2
$$

and, where $O=$ obseved frequencies, $E=$ expected frequencies and $I$ is the number of state, has a probability $P>0.90$. This test shows that the expected and observed distribution do not differ significantly.

Table 10. Comparison of Expected and Actual Distribution.

\begin{tabular}{|c|c|c|c|}
\hline $\begin{array}{c}\text { Gestation } \\
\text { Period (days) }\end{array}$ & $\begin{array}{c}\text { Observed } \\
\text { Frequency }\end{array}$ & $\begin{array}{c}\text { Proportion } \\
\text { Expected }\end{array}$ & $\begin{array}{c}\text { Expected } \\
\text { Frequency }\end{array}$ \\
\hline $210-238$ & 9 & .0781 & 9.45 \\
\hline $238-266$ & 18 & .1664 & 20.19 \\
\hline $266-280$ & 72 & .5364 & 64.90 \\
\hline $280-308$ & 22 & .2184 & 26.42 \\
\hline
\end{tabular}

\subsection{Parity of the Mothers by premature live birth}

The initial probability distribution $P^{t}$ can be found by dividing the frequency of each element by the sum thus $(0.1,0.2,0.5,0.2)$.

$$
\begin{aligned}
& P^{t}=(.1, .2, .5, .1)
\end{aligned}
$$

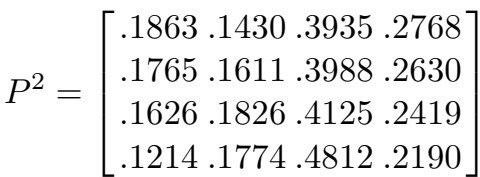

$$
\begin{aligned}
& P^{(t+2)}=\left[\begin{array}{llll}
.1595 & .1733 & .4216 & .2436
\end{array}\right] \text {. }
\end{aligned}
$$


The ultimate equilibrium vector, $P^{e}$, contains four components, so we pre-multiply $P$ by four component row vectors of unknown $\left(x_{1}, x_{2}, x_{3}, x_{4}\right)$.

A system of four equation is produced plus the equation

$$
X_{1}+X_{2}+X_{3}+X_{4}=1
$$

or

$$
\begin{aligned}
& .0250 X_{1}+.0714 X_{2}+.1200 X_{3}+.2352 X_{4}=X_{1} \\
& .1125 X_{1}+.1428 X_{2}+.1000 X_{3}+.3529 X_{4}=X_{2} \\
& .7125 X_{1}+.5774 X_{2}+.4130 X_{3}+.1764 X_{4}=X_{3} \\
& .1500 X_{1}+.2142 X_{2}+.3000 X_{3}+.2352 X_{4}=X_{4}
\end{aligned}
$$

and

$$
X_{1}+X_{2}+X_{3}+X_{4}=1
$$

When these equations are solved simultaneously we get the equilibrium vector $P^{e}$

$$
P^{e}=(.0144, .2005, .4964, .2885) \text {. }
$$

This equation specifies the long term expected properties. A $\chi^{2}$ test of goodness of fit with 3 degrees of freedom where

$$
\chi^{2}=\sum_{I=1,2,3,4} \frac{(O-E)^{2}}{E}=39.2
$$

and, where $O=$ obseved frequencies, $E=$ expected frequencies and $I$ is the number of state, has a probability $P>0.90$. This test shows that the expected and observed distribution differ significantly.

Table 11. Comparison of Expected and Actual Distribution.

\begin{tabular}{|c|c|c|c|}
\hline $\begin{array}{c}\text { Gestation } \\
\text { Period (days) }\end{array}$ & $\begin{array}{c}\text { Observed } \\
\text { Frequency }\end{array}$ & $\begin{array}{c}\text { Proportion } \\
\text { Expected }\end{array}$ & $\begin{array}{c}\text { Expected } \\
\text { Frequency }\end{array}$ \\
\hline $210-238$ & 9 & .0144 & 1.7 \\
\hline $238-266$ & 18 & .2005 & 24.2 \\
\hline $266-280$ & 72 & .4964 & 60.06 \\
\hline $280-308$ & 22 & .2885 & 34 \\
\hline
\end{tabular}

\subsection{HB content of Mothers by premature live birth}

The initial probability distribution $P^{t}$ can be found by dividing the frequency of each element by the sum thus $(0.1,0.2,0.5,0.2)$.

$$
P^{t}=(.1, .2, .5, .1)
$$




$$
\begin{aligned}
& P^{2}=\left[\begin{array}{l}
.0868 .2045 .4996 .2087 \\
.0750 .1944 .5403 .1900 \\
.0679 .1319 .6432 .1563 \\
.0606 .1543 .5519 .2156
\end{array}\right] \\
& P^{(t+2)}=\left[\begin{array}{llll}
.0690 & .1561 & .5900 & .1800
\end{array}\right] .
\end{aligned}
$$

The ultimate equilibrium vector, $P^{e}$, contains four components, so we pre-multiply $P$ by four component row vectors of unknown $\left(x_{1}, x_{2}, x_{3}, x_{4}\right)$.

A system of four equation is produced plus the equation

or

$$
X_{1}+X_{2}+X_{3}+X_{4}=1
$$

$$
\begin{aligned}
& .2000 X_{1}+.1000 X_{2}+.0563 X_{3}+.0500 X_{4}=X_{1} \\
& .1000 X_{1}+.1500 X_{2}+.0985 X_{3}+.3500 X_{4}=X_{2} \\
& .3000 X_{1}+.4000 X_{2}+.7323 X_{3}+.4500 X_{4}=X_{3} \\
& .4000 X_{1}+.3500 X_{2}+.1126 X_{3}+.1500 X_{4}=X_{4}
\end{aligned}
$$

and

$$
X_{1}+X_{2}+X_{3}+X_{4}=1 .
$$

When these equations are solved simultaneously we get the equilibrium vector $P^{e}$

$$
P^{e}=(.06, .23, .5124, .1930)
$$

This equation specifies the long term expected properties. A $\chi^{2}$ test of goodness of fit with 3 degrees of freedom where

$$
\chi^{2}=\sum_{I=1,2,3,4} \frac{(O-E)^{2}}{E}=5.6
$$

and, where $O=$ obseved frequencies, $E=$ expected frequencies and $I$ is the number of state, has a probability $P>0.90$. This test shows that the expected and observed distribution do not differ significantly.

Table 12. Comparison of Expected and Actual Distribution.

\begin{tabular}{|c|c|c|c|}
\hline $\begin{array}{c}\text { Gestation } \\
\text { Period (days) }\end{array}$ & $\begin{array}{c}\text { Observed } \\
\text { Frequency }\end{array}$ & $\begin{array}{c}\text { Proportion } \\
\text { Expected }\end{array}$ & $\begin{array}{c}\text { Expected } \\
\text { Frequency }\end{array}$ \\
\hline $210-238$ & 9 & .06 & 7.26 \\
\hline $238-266$ & 18 & .23 & 27.90 \\
\hline $266-280$ & 72 & .5724 & 62 \\
\hline $280-308$ & 22 & .1930 & 23.5 \\
\hline
\end{tabular}




\subsection{Blood Group of Mothers by premature live birth}

The initial probability distribution $P^{t}$ can be found by dividing the frequency of each element by the sum thus $(0.1,0.2,0.5,0.2)$.

$$
\begin{aligned}
& P^{t}=(.1, .2, .5, .1)
\end{aligned}
$$

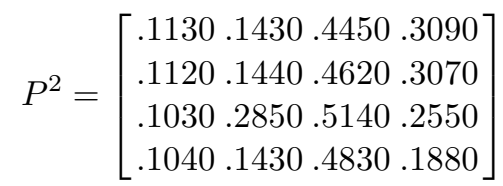

$$
\begin{aligned}
& P^{(t+2)}=\left[\begin{array}{llll}
.1100 & .2100 & .4700 & .2400
\end{array}\right] .
\end{aligned}
$$

The ultimate equilibrium vector, $P^{e}$, contains four components, so we pre-multiply $P$ by four component row vectors of unknown $\left(x_{1}, x_{2}, x_{3}, x_{4}\right)$.

A system of four equation is produced plus the equation

$$
X_{1}+X_{2}+X_{3}+X_{4}=1
$$

or

$$
\begin{aligned}
& 0.06 X_{1}+.06 X_{2}+.13 X_{3}+.1 X_{4}=X_{1} \\
& 0.12 X_{1}+.14 X_{2}+.13 X_{3}+.2 X_{4}=X_{2} \\
& 0.65 X_{1}+.64 X_{2}+.38 X_{3}+.53 X_{4}=X_{3} \\
& 0.18 X_{1}+.17 X_{2}+.38 X_{3}+.17 X_{4}=X_{4}
\end{aligned}
$$

and

$$
X_{1}+X_{2}+X_{3}+X_{4}=1 .
$$

When these equations are solved simultaneously we get the equilibrium vector $P^{e}$

$$
P^{e}=(0.100,0.154,0.500,0.246) \text {. }
$$

This equation specifies the long term expected properties. A $\chi^{2}$ test of goodness of fit with 3 degrees of freedom where

$$
\chi^{2}=\sum_{I=1,2,3,4} \frac{(O-E)^{2}}{E}=4.94
$$

and, where $O=$ obseved frequencies, $E=$ expected frequencies and $I$ is the number of state, has a probability $P>0.90$. This test shows that the expected and observed distribution do not differ significantly.

Table 13. Comparison of Expected and Actual Distribution.

\begin{tabular}{|c|c|c|c|}
\hline $\begin{array}{c}\text { Gestation } \\
\text { Period (days) }\end{array}$ & $\begin{array}{c}\text { Observed } \\
\text { Frequency }\end{array}$ & $\begin{array}{c}\text { Proportion } \\
\text { Expected }\end{array}$ & $\begin{array}{c}\text { Expected } \\
\text { Frequency }\end{array}$ \\
\hline $210-238$ & 9 & .1 & 12.1 \\
\hline $238-266$ & 18 & .154 & 18.6 \\
\hline $266-280$ & 72 & .5 & 60.5 \\
\hline $280-308$ & 22 & .246 & 29.7 \\
\hline
\end{tabular}


Table 14. Mean First Passage Time.

\begin{tabular}{|c|c|c|c|c|c|}
\hline & Age Group & $210-238$ & $238-266$ & $266-280$ & $280-308$ \\
\hline & $15-19$ & 3 & 2.2 & 1.8 & 3 \\
\hline $\mathrm{M}$ & $20-24$ & 2.9 & 2.1 & 1.5 & 3.2 \\
\hline & $25-29$ & 2.8 & 2.3 & 1.9 & 2.7 \\
\hline & 30 -above & 2.6 & 1.9 & 2 & 3.2 \\
\hline & Parity \\
\hline & 0 & 2.9 & 2 & 1.5 & 3.3 \\
\hline & 1 & 2.9 & 2.2 & 1.7 & 3 \\
\hline & 2 & 2.8 & 2.6 & 2 & 2.6 \\
\hline & $3+$ & 2.4 & 2.3 & 2.7 & 2.8 \\
\hline & HB content & 2.9 & 2.7 & 2.1 & 2.3 \\
\hline & 7.9 & 3 & 2.4 & 2 & 2.6 \\
\hline & $8-9.9$ & 2.9 & 2.1 & 1.5 & 3.5 \\
\hline & $10-11.9$ & 2.7 & 1.9 & 2.3 & 2.9 \\
\hline & $12-13$ & & & \\
\hline & Blood Group & 3.05 & 2.2 & 3.67 & 3.76 \\
\hline & A & 2.9 & 2.17 & 3.72 & 3.27 \\
\hline & B & 3.05 & 2.43 & 2.05 & 2.3 \\
\hline & AB & 2.9 & 2.17 & 1.97 & 3.09 \\
\hline & O & \multicolumn{5}{l}{} \\
\hline
\end{tabular}

\section{Conclusion}

In this study the long term distribution of the duration of the gestation of mature and premature biological and bio-demographic characters are analysed. From this study it is observed that, for mature live birth there is no significant difference between age group and gestation period. Also it is observed that there is a significant difference between gestation period and a set of Blood group, HB and Parity. For the given data of premature live birth there is significant difference between parity and gestation period and no significant difference between gestation period and Blood group, Age group, HB content. The biological and bio-demographic characters are of vital factors in the premature live birth.

\section{Acknowledgements}

We, the authors wish to thank the refrees for their valuable comments which helped us in improving the quality and credibility of the paper. 


\section{References}

[1] D. Bartholomew, Stochastic Models for Social Processes, Second edition, Wiley, New York, 1973.

[2] J. Kemeny and Snell, Finite Markov Chain, Van Nostrand, New York, 1960.

[3] C. A. Prithiviraj and K. Senthamarai Kannan, Birth Intervals in Human Fertility Analysis, Paper presented in $13^{\text {th }}$ Annual Conference of Ramanujam Mathematical Society, held in Manonmaniam Sundaranar University, Tirunelveli, 1998.

[4] Srinivasan K. Pathak and A. B. Anand Pandey, A Study of fertility through Birth Interval Analysis, IIPS Bombay, 1986.

[5] Senthamarai Kannan, D. Nagarajan and T. Tamizh Chelvam, Regression model of human gestation period for mature and premature live birth, Proceedings in NSSMA Conference at Annamalai University, (2002), 298-311.

Manonmaniam Sundaranar University, Tirunelveli, Tamilnadu, India.

St. Joseph's College of Engineering, Chennai - 600 119, Tamilnadu, India.

E-mail: dnrmsu2002@yahoo.com

Manonmaniam Sundaranar University, Tirunelveli, Tamilnadu, India. 